\title{
PSYCHOSOCIAL WORK DIMENSIONS, PERSONALITY, AND BODY MASS INDEX: SEX DIFFERENCES
}

\author{
ANGEL BLANCH ${ }^{1,2}$ and ANTON ALUJA ${ }^{1,2}$ \\ ${ }^{1}$ University of Lleida, Lleida, Spain \\ Department of Pedagogy and Psychology \\ ${ }^{2}$ Institute of Biomedical Research (IRB Lleida), Lleida, Spain
}

\begin{abstract}
Objectives: The association between psychosocial work dimensions (i.e. demand and control) and obesity has been found to be inconclusive, indicating that individual differences factors might also contribute to explain the variability in BMI. Materials and Methods: The interaction between work dimensions and personality variables in a group of male and female workers $(\mathrm{N}=506)$, and its associations with BMI were analyzed with a cross-sectional study with self-report data. Hierarchical regression analyses were used to predict the BMI levels from work and individual differences variables and their interactions for males and females. Results: The main effects of personality variables were not significant, physical workload interacted with neuroticism for males, whereas control interacted with activity for females. Conclusions: Psychosocial work dimensions and personality traits were related to BMI for men and women. These outcomes reinforce the notion that different models might account for the explanatory mechanisms of BMI in regard to sex.
\end{abstract}

\section{Keywords:}

BMI, Work demand and control, Personality

\section{INTRODUCTION}

Overweight is an important risk factor for cardiovascular disease, diabetes, cancer, and other health-related problems, and has become one of the most relevant public health problems in contemporary societies. In addition to this, the general health costs for the society and the economic costs of obesity in the workplace in terms of absenteeism, sick leave, or job injuries have also been highlighted [1,2], eliciting the implementation of obesity prevention programs at worksites [3]. Recent longitudinal research in industrialized regions such as Europe [4,5], the United States [6], and Japan [7] has attempted to link psychosocial work stressors with weight gains. The findings in these studies have been usually interpreted within the
Demand - Control (DC) model [8], suggesting that high job demands, low job control, and poor social relationships at work could be related to significant gains in the body mass index (BMI) and increased abdominal obesity.

The psychological correlates of excess weight are not well documented [9,10], therefore, a relevant question is whether the psychological correlates of obesity might vary among individuals. Evidence points out to demographic variables, individual differences, and lifestyle factors that might influence coping with psychosocial work strain and the subsequent development of obesity [11-14]. For instance, sex might be a consistent moderator in the association of BMI with the DC psychosocial work dimensions, as indicated by several

Received: September 9, 2012. Accepted: April 25, 2013.

Corresponding author: A. Blanch, Department of Pedagogy and Psychology, Faculty of Education, University of Lleida, Avda de l'Estudi General, 4, 25001 Lleida (Catalonia), Spain (e-mail: ablanch@pip.udl.cat). 
works reporting variations in the association of stressors with BMI as a function of sex [6,9,15-19]. Moreover, there are dispositional individual differences associated with the body weight for males and females, whereas a greater social stigma is usually attributed to women than to men concerning being overweight $[9,15]$. Furthermore, a number of behavioral, emotional, and cognitive characteristics are deeply rooted in weight control disturbances for many people [11,20]. For instance, overweight has been associated with paranoid, antisocial, and avoidant personality disorders in women, with men displaying lower rates of the paranoid personality disorder, whereas underweight women showed higher odds ratios than men as regards the schizoid personality disorder [21]. Besides, different personality traits have been associated with BMI: a positive relation of neuroticism and extraversion for females and males, respectively, and a negative relation with agreeableness and conscientiousness for both males and females [15,22]. In addition, impulsiveness and conscientiousness (low self-discipline) have also been positively and negatively related to BMI $[20,23]$. To sum up, higher BMI levels have been related to increased neuroticism in women and to increased extraversion and psychoticism in men. Several empirical works suggest that addressing the relationship of psychosocial work dimensions with BMI through sex-specific models is utterly warranted. Furthermore, the moderating role of individual differences in personality might provide a more comprehensive approach to study the variations in BMI due to its psychological correlates [16,24]. However, as far as we know, no studies have explicitly analyzed whether psychosocial work dimensions and personality could be intertwined when associated with BMI. Therefore, the present study sought to assess under what exact individual differences in personality, the DC psychosocial work dimensions might be related to BMI for both males and females.

\section{METHOD}

\section{Participants and procedure}

The participants filled in self-report questionnaires that had been distributed at administration, management, technical and education services job posts in private and public companies in a mid-size city in Catalonia (Spain). The questionnaires were collected at each individual's workplace after two weeks. In this way, data from $322 \mathrm{fe-}$ male, and 184 male full-time workers were obtained. The participants worked approximately $40 \mathrm{~h}$ per week.

\section{Measures}

Body Mass Index

Body Mass Index (BMI) is a measure used to evaluate obesity, usually expressed as $\mathrm{kg} / \mathrm{m}^{2}$ - weight in kilograms divided by height in meters squared. Both parameters were self-reported by the participants, even though these types of BMI measures tend to correlate with the measures of BMI when being directly estimated [25].

\section{Demographic factors}

Age and education were used as the control variables. Age was measured in years. Education was measured with one item asking the top education level attained, and it was coded from 1 (elementary school) to 6 (doctoral studies).

\section{Work variables}

Three job characteristics were evaluated with the Job Content Questionnaire [26]:

1. Psychological work demand (9 items): measures the degree of psychological workload (I have sufficient time to finish the work).

2. Physical workload (3 items): evaluates the degree of physical workload required by one's job (My job requires a lot of physical effort).

3. Control (9 items): assesses the degree of skill utilization at the workplace (My job requires me to learn new things), and the availability to make decisions over 
one's work (My job allows me to make a lot of decisions on my own).

The items were answered on a four-point Likert type scale, from one (strongly disagree) to four (strongly agree).

Personality variables

Five personality dimensions were assessed with a 50-item short version of the Zuckerman-Kuhlman Personality Questionnaire [27,28]:

1. Impulsive Sensation Seeking (ImpSS) - it describes the lack of planning and seeking new experiences, change and novelty.

2. Neuroticism-Anxiety (N-Anx) - this measure describes distress, lack of emotional stability, and self-confidence.

3. Aggression-Hostility (Agg-Host) - it reflects a predisposition to express verbal aggression, and coarse or even antisocial behaviour.

4. Activity (Act) - this measure describes a high level of individual energy and a preference for an active life with challenging activities.

5. Sociability (Sy) - this scale describes a preference for being with others, as opposed to performing solitary activities.

All subscales were composed of 10 items and were answered based on a true - false format.

\section{Data analyses}

The data were analyzed taking into account sex-specific models to assess the interactions between work and personality variables in the prediction of BMI. All data analyses were split for males and females [16]. First, we obtained partial correlations of work and personality dimensions with BMI controled for age. Second, we selected:

1) the workload variable (psychological or physical) with the highest partial correlation with BMI; 2) the control variable; and 3) the two personality variables with the highest partial correlations with BMI. Third, these variables were entered into a hierarchical moderated regression models with BMI as the dependent variable [29]. Four steps of explanatory variables were progressively entered into the regression models: 1) demographics (age and education);2) work; 3) personality; and 4) the interactions of work by personality variables.

\section{RESULTS}

Table 1 shows means, standard deviations, reliabilities, effect sizes, and partial correlations of the study variables. Alpha internal consistency reliabilities of self-report instruments were acceptable, ranging from 0.68 to 0.85 . There were small to medium effect sizes for male and female mean differences in age (0.33) and sociability $(-0.34)$, and large for BMI (0.97) [30]. The higher partial correlations with BMI noted for males were those with physical workload (0.13), neuroticism (0.07), and sociability (0.11), and for females with physical workload (0.14), impulsive sensation seeking $(-0.08)$, and activity $(-0.08)$. These were the variables used to build moderated regression models for males and females.

Table 2 shows unstandardized regression coefficients and coefficients of determination $\left(R^{2}\right)$ increments at each variable input. The first half of Table 2 shows these values when the personality variables of neuroticism and sociability were introduced, whereas the second half of Table 2 displays the same information for the personality variables of impulsive sensation seeking and activity. Both regression models are displayed for males and females. For males, there were significant main effects for age $(0.08, \mathrm{p}<0.01)$, whereas for females there were significant main effects also for age $(0.12$, $p<0.001)$, education $(-0.28, p<0.05)$, and physical work$\operatorname{load}(0.23, \mathrm{p}<0.05)$. There was a significant interaction for males: physical workload $\times$ neuroticism $(0.21, \mathrm{p}<0.01)$. Furthermore, there were two significant interactions for females: control $x$ impulsive sensation seeking $(-0.01, \mathrm{p}<0.05)$, and control $\times$ activity $(-0.03, \mathrm{p}<0.01)$, although in accordance with a Bonferroni correction, only 
Table 1. Descriptive statistics, alpha reliabilities, effect sizes, and partial correlation coefficients with BMI adjusted for age

\begin{tabular}{|c|c|c|c|c|c|c|c|c|c|}
\hline \multirow{2}{*}{ Variable } & \multicolumn{3}{|c|}{$\begin{array}{c}\text { Males } \\
(\mathrm{N}=184)\end{array}$} & \multicolumn{3}{|c|}{$\begin{array}{l}\text { Females } \\
(\mathrm{N}=322)\end{array}$} & \multirow[t]{2}{*}{$d$} & \multicolumn{2}{|c|}{$\begin{array}{c}\text { Partial correlations } \\
\text { with BMI }\end{array}$} \\
\hline & $\mathrm{M}$ & SD & $\alpha$ & M & SD & $\alpha$ & & males & females \\
\hline Age & 41.33 & 9.06 & - & 38.29 & 9.20 & - & 0.33 & $0.23 * *$ & $0.40^{* * *}$ \\
\hline Education & 3.76 & 1.29 & - & 3.85 & 1.12 & - & -0.08 & -0.00 & -0.11 \\
\hline Psychological work demand & 7.84 & 3.59 & 0.75 & 8.61 & 3.64 & 0.75 & -0.21 & -0.03 & 0.09 \\
\hline Physical workload & 4.98 & 1.53 & 0.72 & 4.87 & 1.54 & 0.72 & 0.07 & 0.13 & $0.14^{*}$ \\
\hline Control & 37.09 & 5.96 & 0.85 & 36.72 & 5.81 & 0.82 & 0.06 & 0.08 & 0.08 \\
\hline Impulsive sensation seeking & 4.57 & 2.78 & 0.77 & 4.10 & 2.65 & 0.76 & 0.17 & 0.03 & -0.08 \\
\hline Neuroticism & 2.68 & 2.25 & 0.74 & 3.23 & 2.63 & 0.80 & -0.22 & 0.07 & 0.01 \\
\hline Aggression-Hostility & 4.25 & 2.51 & 0.70 & 4.00 & 2.45 & 0.68 & 0.10 & 0.06 & -0.05 \\
\hline Activity & 5.03 & 2.58 & 0.72 & 4.61 & 2.68 & 0.76 & 0.16 & 0.04 & -0.08 \\
\hline Sociability & 4.55 & 2.46 & 0.70 & 5.36 & 2.35 & 0.69 & -0.34 & 0.11 & 0.03 \\
\hline BMI & 25.67 & 2.98 & - & 22.77 & 2.98 & - & 0.97 & - & - \\
\hline
\end{tabular}

$\mathrm{M}$ - mean; SD - standard deviation.

Age and Body Mass Index (BMI) are Pearson correlation coefficients;

${ }^{*} \mathrm{p}<0.05 ;{ }^{* *} \mathrm{p}<0.01 ;{ }^{* * *} \mathrm{p}<0.001$.

Table 2. Moderated regression analysis with BMI as the dependent variable

\begin{tabular}{|c|c|c|c|c|c|c|}
\hline \multirow{2}{*}{ Predictor } & \multicolumn{3}{|c|}{ Males $(\mathrm{N}=184)$} & \multicolumn{3}{|c|}{ Females $(\mathrm{N}=322)$} \\
\hline & $b$ & $R^{2}$ & $F$ & $b$ & $R^{2}$ & $F$ \\
\hline \multicolumn{7}{|l|}{ Parameters } \\
\hline $\mathrm{K}$ & $25.52^{* * *}$ & - & - & $22.93^{* * *}$ & - & - \\
\hline age & $0.08^{* *}$ & $0.05^{* *}$ & $10.39^{* *}$ & $0.12^{* * *}$ & $0.17^{* * *}$ & $63.05^{* * *}$ \\
\hline education & -0.00 & 0.05 & 0.00 & $-0.28^{*}$ & $0.18^{*}$ & $3.81^{*}$ \\
\hline physical workload & 0.27 & 0.07 & 3.44 & $0.23^{*}$ & $0.19^{*}$ & $4.93^{*}$ \\
\hline control & 0.04 & 0.08 & 1.28 & 0.05 & 0.20 & 3.42 \\
\hline \multicolumn{7}{|l|}{ Neuroticism and sociability } \\
\hline neuroticism & 0.12 & 0.08 & 1.04 & 0.03 & 0.20 & 0.14 \\
\hline sociability & 0.10 & 0.09 & 1.25 & 0.03 & 0.20 & 0.19 \\
\hline physical workload $\times$ neuroticism & $0.21^{* *}$ & $0.13^{* *}$ & $7.37^{* *}$ & 0.03 & 0.20 & 0.64 \\
\hline control $\times$ neuroticism & -0.02 & 0.14 & 2.02 & -0.00 & 0.20 & 0.04 \\
\hline physical workload $\times$ sociability & 0.01 & 0.14 & 0.03 & -0.04 & 0.20 & 0.66 \\
\hline control $\times$ sociability & 0.01 & 0.14 & 0.09 & 0.00 & 0.20 & 0.04 \\
\hline \multicolumn{7}{|l|}{ Impulsive sensation seeking and activity } \\
\hline impulsive sensation seeking & -0.01 & 0.08 & 0.01 & -0.09 & 0.21 & 3.32 \\
\hline activity & 0.00 & 0.08 & 0.00 & -0.09 & 0.21 & 2.16 \\
\hline $\begin{array}{l}\text { physical workload } \times \text { impulsive sensation } \\
\text { seeking }\end{array}$ & 0.08 & 0.10 & 3.75 & -0.04 & 0.22 & 1.47 \\
\hline control $\times$ impulsive sensation seeking & -0.01 & 0.10 & 0.01 & $-0.01 *$ & $0.23^{*}$ & $4.91^{*}$ \\
\hline
\end{tabular}


Table 2. Moderated regression analysis with BMI as the dependent variable - cont.

\begin{tabular}{lcccccc}
\hline \multirow{2}{*}{\multicolumn{1}{c}{ Predictor }} & \multicolumn{3}{c}{ Males $(\mathrm{N}=184)$} & \multicolumn{3}{c}{ Females $(\mathrm{N}=322)$} \\
\cline { 2 - 7 } & $b$ & $R^{2}$ & $F$ & $b$ & $R^{2}$ & $F$ \\
\hline physical workload $\times$ activity & 0.09 & 0.11 & 2.07 & -0.02 & 0.23 & 0.33 \\
control $\times$ activity & 0.02 & 0.12 & 2.20 & $-0.03^{* *}$ & $0.25^{* *}$ & $7.97^{* *}$ \\
\hline
\end{tabular}

Unstandardized regression coefficients belong to the step at which the variable was initially into entered the equation.

$\mathrm{K}$ - the constant in the regression equation; $R^{2}$ - indicates the progressive change in the coefficient as each variable was entered into the equation. * $\mathrm{p}<0.05 ; * \mathrm{p}<0.01 ; * * \mathrm{p}<0.001$.

Table 3. Associations of physical workload by neuroticism (males) and control by activity (females) with BMI

\begin{tabular}{lcc}
\hline $\begin{array}{c}\text { Personality } \\
\pm 1 / 2 \text { SD }\end{array}$ & $\begin{array}{c}\text { Physical workload } \times \\
\text { neuroticism } \\
\text { (males) }\end{array}$ & $\begin{array}{c}\text { Control } \times \text { activity } \\
\text { (females) }\end{array}$ \\
\hline-1 & -0.16 & $0.12^{* * *}$ \\
-0.5 & 0.06 & $0.08^{* * *}$ \\
0 & 0.27 & 0.04 \\
0.5 & $0.49^{* *}$ & 0.00 \\
1 & $0.70^{* *}$ & -0.04 \\
\hline
\end{tabular}

Personality $\pm 1 / 2$ SD $=$ Range of standard deviations in the personality variable.

** $\mathrm{p}<0.01 ; * * \mathrm{p}<0.001$.

the control $\times$ activity interaction was considered significant: $0.05 \alpha$ level $/ 4$ interactions $=0.0125$ [31].

Table 3 shows the simple slopes at five levels of the personality variables (1/2 SD), neuroticism for males and activity for females: one standard deviation above and below the mean, half standard deviation above and below the mean, and at the mean centered value of zero. For males (top plot in Figure 1), the simple slopes indicated a positive significant association of physical workload with BMI at the higher levels of neuroticism (0.49 and $0.70, p<0.01)$. For females (bottom plot in Figure 1), the simple slopes showed a positive significant association of control with BMI at the lower levels of activity $(0.12$ and $0.08, \mathrm{p}<0.001)$. Thus, physical workload was predictive of BMI variations only when neuroticism was high for males, whereas control was a consistent predictor of BMI variations only when activity was low for females.
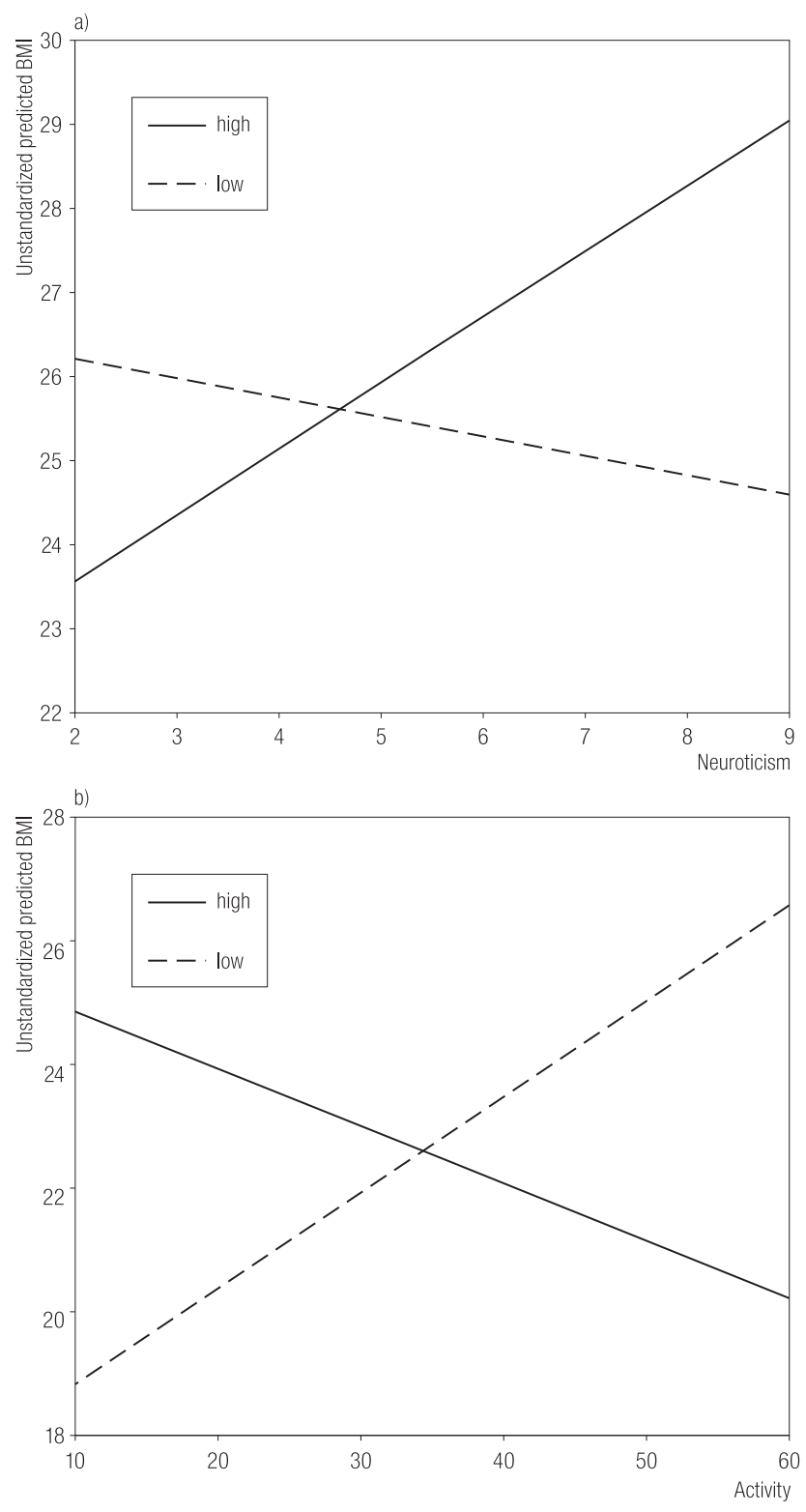

Fig. 1. Interaction plots: a) physical workload with neuroticism for males, b) control with activity for females 


\section{DISCUSSION}

The present study evaluated the interrelationships between the DC main psychosocial dimensions, and personality variables in the prediction of BMI for each sex. The outcomes suggest that different person vs. situation mechanisms modeled as personality by work variables interactions might contribute to account for the variation in BMI for men and women. However, these findings may be conceived as preliminary evidence of how psychosocial work dimensions derived from the DC model might interact with the personality variables in the explanation of BMI when sex is also considered as a moderating demographic variable. Overall, the processes that might contribute to BMI variations for males and females differed on the work and personality variables interplay, an outcome that somehow substantiates the past reports in this field of research [15,16].

The significant physical workload by neuroticism interaction found for males suggests a consistent positive association of physical workload with BMI at high levels in the personality factor of neuroticism. Male workers reporting a greater physical effort devoted to their jobs also reported increased BMI only when scoring high on the neuroticism personality dimension. Thus, male workers with high physical workload, low emotional stability, and lack of selfconfidence might be more prone to display high BMI levels. Even though past research works did not test for any interactions with psychosocial work dimensions, this was somewhat contrary to what had been previously reported when considering sex, because neuroticism and BMI had been linked only for females in the past research $[15,16]$. However, the association of neuroticism with BMI for women could also be extended to men because feelings of anxiety and depression embedded in the neuroticism dimension might contribute to poorer health habits such as eating or drinking to cope with higher workload levels, or just neglecting to exercise on a regular basis [15]. Besides, it should be recalled that neuroticism is an individual disposition to undergo negative emotions and vulnerability to stress irrespectively of sex, which has been consistently related with deleterious behaviors and lack of more positive healthy habits [32].

The control by activity interaction for females indicates in turn a significant positive association of control with BMI at low levels in the personality factor of activity. In accordance with the DC model, lower levels of control are associated with job stress and other health-related problems [33], while epidemiologic studies have also found significant associations of the DC dimensions with BMI and abdominal obesity (e.g. high job demands, low job control, and poor social relations). Nevertheless, female workers reporting higher work control, in terms of high skill discretion and the availability to make decisions at the workplace, also reported high BMI levels when scoring low in the activity variable. Thus, female workers with high work control, a more relaxed disposition towards life, and sedentary or even passive attitudes might be more prone to display high BMI levels. Higher scores in activity define a higher level of individual energy and active life, therefore women with less personal energy and no active life might be more prone to increases in BMI, even with better opportunities of control availability at the workplace. This finding corroborates past research indicating a negative relationship of self-discipline, the ability to stay on a task and persevere, with BMI. Moreover, highly active women might be more willing to take care of diet and exercise habits to maintain reasonable body weight, independently of the levels of control at the workplace [15,20,34].

The possible reasons for why each of these interactions was only significant for either males or females remain largely unknown. First, this study was exploratory and included the assessment of individual dispositions from a model that, as far as it is known, had not been used before in this field of research. Secondly, there is a paucity of studies addressing the interrelationships amongst the psychosocial work environment factors, individual differences in personality, and BMI or related health outcomes. Therefore, 
providing an interpretation about the lack of significance of each interaction for the respective sex could be highly speculative without a wider and more consistent theoretical and empirical basis.

The measurement of personality in this study was approached from the alternative big five model, rather than from those used in past research attempts analyzing its relationship with BMI $[15,20,22,24,28]$. This personality model is rooted within the psychobiological basis of personality and therefore, can be perhaps more adequate to study biology-related health outcomes, such as BMI, than descriptive personality models relying on a lexical approach. In addition, attempting to contrast specific hypotheses across different personality models might contribute to delineate future hypotheses and shed further light regarding the association of individual dispositions with BMI. For instance, the lack of replication of prior findings about the association of neuroticism with BMI could perhaps be due to the use of different personality measurements. Nevertheless, additional research would be needed to confirm whether there is no association of neuroticism with BMI when using the currently applied personality model, taking into consideration the inherent drawbacks of this kind of studies.

Some limitations in the present work should be acknowledged in order to address future research directions. First, the cross-sectional design of the present study does not allow the assumption of causal inferences concerning the precedence of the studied variables. For instance, there can be difficulties when attempting to pinpoint personality and BMI as the cause and effect in this type of designs [15]. Thus, longitudinal studies would be necessary to corroborate the causal assumptions derived from the present study. Secondly, it could be argued that the sample size on which these results are based is rather small. Most past works on the relation of workload and personality with obesity have used much more sizeable samples. Third and related to the point above, the sample in this study was derived the services sector, whereas past research had considered a more diverse occupational background.

This study suggests that the processes linking psychosocial work dimensions with BMI variations in men and women might be due to the moderating effects of individual differences in personality. To the best of our knowledge, this is the first study that provides evidence suggesting that BMI, and perhaps also obesity, might be partially explained for men and women based on the interaction between psychosocial work dimensions and personality dispositions. This general outcome might have implications for the targeting of risk populations in public health interventions. Further research work is needed, however, to corroborate, disclaim, or suggest alternative complex connections amongst the psychosocial work environment dimensions, personality tendencies and important healthrelated outcomes such as obesity and BMI.

\section{REFERENCES}

1. Schmier JK, Jones ML, Halpern MT. Cost of obesity in the workplace. Scand J Work Environ Health. 2006;32(1):5-11.

2. Moens G, Van Gaal L, Muls E, Viaene B, Jacques P. Body mass index and health among the working population. Eur J Public Health. 1999;9(2):119-23.

3. Yamada Y, Ishizaki M, Tsuritani I. Prevention of weight gain and obesity in occupational populations: A new target of health promotion services at worksites. J Occup Health. 2002;44:373-84.

4. Berset M, Semmer NK, Elfering A, Jacobshagen N, Meier LL. Does stress at work make you gain weight? A two-year longitudinal study. Scand J Work Environ Health. 2011;37(1):45-53.

5. Hannerz H, Albertsen K, Nielsen ML, Tüchsen F, Burr H. Occupational factors and 5-year weight change among men in a Danish national cohort. Health Psychol. 2004;23(3):283-8.

6. Block JP, He Y, Zaslavsky AM, Ding L, Ayanian JZ. Psychosocial stress and change in weight among US adults. Am J Epidemiol. 2009;170(2):181-92. 
7. Ishizaki M, Nakagawa H, Morikawa Y, Honda R, Yamada Y, Kawakami N, et al. Influence of job strain on changes in body mass index and waist circumference - 6-year longitudinal study. Scand J Work Environ Health. 2008;34(4): 288-96.

8. Karasek RA. Job demands, job decision latitude, and mental strain: Implications for job redesign. Adm Sci Q. 1979;24:285-308.

9. Friedman MA, Brownell KD. Psychological correlates of obesity: Moving to the next research generation. Psychol Bull. 1995;117(1):3-20.

10. Wadden TA, Brownell KD, Foster GD. Obesity: Responding to the global epidemic. J Consult Clin Psychol. 2002;70(3):510-25.

11. Corley J, Gow AJ, Starr JM, Deary IJ. Is body mass index in old age related to cognitive abilities? The Lothian Birth Cohort 1936 Study. Psychol Aging. 2010;25(4):867-75.

12. Overgaard D, Gyntelberg F, Heitmann BL. Psychological workload and body weight: Is there an association? A review of the literature. Occup Med. 2004;54:35-41.

13. Williams P, Suchy Y, Rau HK. Individual differences in executive functioning: Implications for stress regulation. Ann Behav Med. 2009;37(2):126-40.

14. Jonassaint CR, Siegler IC, Barefoot JC, Edwards CL, Williams RB. Low life course socioeconomic status (SES) is associated with negative NEO PI-R personality patterns. Int J Behav Med. 2011;18(1):13-21.

15. Brummett BH, Babyak MA, Williams RB, Barefoot JC, Costa PT, Siegler HC. NEO personality domains and gender predict levels and trends in body mass index over 14 years during midlife. J Res Pers. 2006;40(3):222-36.

16. Faith MS, Flint J, Fairburn CG, Goodwin GM, Allison DB. Gender differences in the relationship between personality dimensions and relative body weight. Obes Res. 2001;9(10):647-50.

17. Hellerstedt WL, Jeffery RW. The association of job strain and health behaviours in men and women. Int J Epidemiol. 1997;26(3):575-83.
18. Rosmond R, Nilsson A, Björntorp P. Psychiatric ill health and distribution of body fat mass among female immigrants in Sweden. Public Health. 2000;114(1):45-51.

19. Butler P, Mellor D. Role of personal factors in women's self-reported weight management behaviour. Public Health. 2006;120(5):383-92.

20. Terracciano A, Sutin AR, McCrae RR, Deiana B, Ferrucci L, Schlessinger D, et al. Facets of personality linked to underweight and overweight. Psychosom Med. 2009;70(6):682-9.

21. Mather AA, Cox BJ, Enns MW, Sareen J. Associations between body weight and personality disorders in a nationally representative sample. Psychosom Med. 2008;70(9):1012-9.

22. Costa PT, McCrae RR. Revised NEO Personality Inventory (NEO-PI-R) and NEO Five-Factor Inventory (NEO-FFI). Odessa, FL: Psychological Assessment Resources; 1992.

23. Chapman BP, Fiscella K, Kawachi I, Duberstein P, Coletta M. Can the influence of childhood socioeconomic status on men's and women's adult body mass be explained by adult socioeconomic status or personality? Findings from a national sample. Health Psychol. 2009;28(4):419-27.

24. Eysenck HJ. The biological bases of personality. Springfield, IL: Charles C. Thomas; 1967.

25. Heymsfield SB, Heshka S, Allison DB, Pierson RN. Body composition. In: Allison DB, editor. Handbook of measurement methods for the assessment of eating behaviours and weight related problems. Newbury Park, CA: Sage Publications; 1995.

26. Karasek R, Brisson C, Kawakami N, Houtman I, Bongers P, Amick B. The Job Content Questionnaire (JCQ): An instrument for internationally comparative assessments of psychosocial job characteristics. J Occup Health Psychol. 1998;3(4):322-55.

27. Aluja A, Rossier J, García LF, Angleitner A, Kuhlman M, Zuckerman M. A cross-cultural shortened form of the ZKPQ (ZKPQ-50-cc) adapted to English, French, German, and Spanish languages. Pers Individ Dif. 2006;41:619-28.

28. Zuckerman M. Psychobiology of personality. New York: Cambridge University Press; 2005. 
29. Aiken LS, West SG. Multiple regression: Testing and interpreting interactions. Newbury Park: Sage Publications; 1991.

30. Cohen J. Statistical power analysis for the behavioural sciences. New Jersey: Lawrence Erlbaum Associates, Inc.; 1988.

31. Holland BS, DiPonzio Copenhaver M. Improved Bonferroni-type multiple testing procedures. Psychol Bull. 1988;104(1):145-9.

32. Booth-Kewley S, Vickers R. Associations between major domains of personality and health behavior. J Pers. 1994;62(3):281-98.
33. Karasek RA, Theorell T. Healthy work: Stress, productivity, and the reconstruction of working life. New York: Basic Books; 1990.

34. O'Connor DB, Conner M, Jones F, McMillan B, Ferguson E. Exploring the benefits of conscientiousness: An investigation of the role of daily stressors and health behaviors. Ann Behav Med. 2009;37(2):184-96.

This work is available in Open Access model and licensed under a Creative Commons Attribution-NonCommercial 3.0 Poland License - http://creativecommons.org/ licenses/by-nc/3.0/pl/deed.en. 